\title{
Ruta gastronómica del Callejón de Huaylas
}

(") Mauro Granados Maguiño

e-mail: d180052@unmsm.edu.pe

\section{INTRODUCCION}

El presente trabajo tiene por objetivo diseñar la ruta gastronómica del Callejón de Huaylas identificando sus productos agrícolas, sus formas de preparar alimentos servirlos y valorarlos.

Descripción etnográfica y sociográfica de los lugares entorno físico y cultural, vivencias culturales del suscrito en base a la observación como integrante de la actividad turística en la región.

\section{DESCRIPCION FISICA DE LA RUTA}

Ubicación: El departamento de Ancash está situado al norte de Lima entre el Océano Pacifico y el río Marañón. Limita por el Este con el Departamento de Huánuco, por el Oeste con el Océano Pacífico, por el Norte con el departamento de Trujillo y por el Sur con el departamento de Lima.

Distancias: Huaraz a Lima $408 \mathrm{Km}$. Huaraz a Trujillo $335 \mathrm{Km}$. Huaraz a Cajamarca $636 \mathrm{Km}$.

Clima: Templado y semitropical. Los días son calurosos y las noches frías. La época de lluvias es desde diciembre hasta abril. Entre mayo y noviembre se disfruta un clima agradable en toda la región denominado "verano andino"

Superficie: $35,826 \mathrm{Km} 2$.

Temperatura: Media anual $16.2^{\circ} \mathrm{C}$.

Red. Vial: $4429 \mathrm{Km}$.

Poblacion: 1'014,218 hab.

Extension: 40,627.04 km2
Capital: Huaraz, está ubicada en la región nor-andina al centro del valle Santa, al centro del valle Santa, entre la Cordilleras Blanca y Negra. Se encuentra a $400 \mathrm{~km}$. de Lima.

Altitud: 3,091 m.s.n.m.

Geografía: Ancash es un departamento de contrastes, tiene grandes valles longitudinales: el Callejón de Huaylas $y$ el Alto Marañon Selvático, asimismo, sus arenales costeños y su mar. Frente a las alturas del Huascarán se encuentra el mar ancashino, la fosa de Chimbote con $6,263 \mathrm{~m}$. de profundidad. El accidentado territorio del departamento es atravesado por dos cordilleras en el lado occidental la Cordillera Negra y el oniental la Cordillera Blanca, entre las cuales corre el río Santa por el denominado callejón de Huaylas. Este, al estrecharse, forma el Cañón del Pato.

Cinco son las rutas principales que recorren el relieve de este departamento: Una es la carretera Panamericana Norte, que recorre longitudinalmente la Costa de Ancash. Hay tres carreteras transversales que conectan la costa con la región de la sierra (fundamentalmente con el Callejón de Huaylas) : Pativilca-Huallanca, Casma-Huaraz y Chimbote-Huallanca. $Y$ existe una carretera que recorre longitudinalmente el llamado Callejón de Conchucos, al este de la Cordillera Blanca.

\section{RUTA: CARRETERA PANAMERICANA NORTE}

Siguiendo la carretera Panamericana Norte desde Lima, el territorio del Departamento de Ancash comienza después de pasar por la fortaleza de Paramonga y luego de cruzar el río Fortaleza (a $205 \mathrm{Km}$. De Lima) entre dilatadas planicies sembradas de caña de azúcar. En toda la extensión de la costa ancashina, desde el río Fortaleza hasta el río Santa en su límite septentrional con el departamento de La Libertad, se aprecia la gran inf́luencia que ejerce el mar en la región costera del pals. 
especialmente saltante en la costa de Ancash, la Corriente Peruana o de Humboldt y la contracorriente del Niño afectan notoriamente, a veces de manera trágica, en diversas épocas del año y de distinto modo, la vida y la economía regional.

Los ríos.- De los ríos de la costa, el único que tiene agua todo el año es el río Santa, por provenir sus fuentes de los glaciares y lagunas de la cordillera Blanca.

Los demás ríos son, como los de la mayoría de la costa peruana, de un régimen totalmente irregular, pendiente de las lluvias en la sierra o del avance de la Corriente del Niño. El río Santa, nace en la laguna de Conococha en la Cordillera Blanca, recorre el Callejón de Huaylas en toda su extensión y, luego de cortar a la Cordillera Negra en el imponente Cañón del Pato, desemboca en las planicies del Santa, después de un recorrido de $336 \mathrm{Km}$.

\section{$2^{\circ}$ RUTA: PATIVILCA - CARAZ - HUALLANCA}

El histórico pueblo de Pativilca se encuentra a 202 $\mathrm{Km}$. de Lima, por la Panamericana Norte, donde Simón Bolívar planificara su campaña libertadora del Perú. De allf parte la carretera que conduce al Callejón de Huaylas totalmente asfaltada, se desarrolla entre amplios campos sembrados de caña de azúcar en dilatadas planicies, paralelas al cauce del río Fortaleza. Son cerca de $20 \mathrm{Km}$. de carretera. A partir del pueblo de Huaricanga se ingresa en el departamento de Ancash y se comienza el ascenso de las primeras estribaciones de la cordillera Negra. Este lento ascenso se realiza por un tramo de $50 \mathrm{Km}$, hasta que comienza a empinarse abruptamente poco después de Chasquitambo y Chaucayán ( $\mathrm{Km} \mathrm{65),} \mathrm{multiplicándose}$ las curvas y los serpentines en planos muy inclinados pero seguros.

El Callejón de Huaylas.- Luego de cruzar el pueblo de Colca, a 2,000 msnm, se asciende hasta Cajatay, donde ya comienzan a emerger en la soledad del paisaje las primeras montañas nevadas de la Cordillera Blanca. En la cumbre, a 3,945 msnm, hacia la mano derecha se encuentra la laguna de Conococha, principal fuente del río Santa. Se desciende suavemente, para ingresar directamente en el Callejón de Huaylas, demarcado en su sector este por la Cordillera Blanca y al oeste por la cordillera Negra, en el curso superior del río Santa. Al sur están las cumbres de la Cordillera de Huayhuash. límite con Huánuco. Desde la altura se divisa la carretera que desciende hacia Catac hay $49 \mathrm{~m}$.

Siguiendo por la frígida puna por pastos de ichu durante $10 \mathrm{Km}$, se llega a Recuay, ciudad pórtico del Callejón de Huaylas, que es en realidad un gran valle de ensueño, con una sucesión de paisajes agrestes que se encuentran entre los más hermosos del mundo, enmarcados en una gigantesca grandiosidad de cumbres nevadas, campos floridos, lagunas azules, pueblos y peculiares campesinos con vestidos típicos muy variados y coloridos.

Recuay.- Se encuentra al borde del río Santa, a 3422 msnm, capital de la provincia de Recuay. Posee las aguas minerales y termales de Conococha, Ucuschaca, Pachacoto. Pumapampa, Burgos y Otuco. Las lagunas de Querococha y Conococha se encuentran dentro de los límites de la provincia, al igual que el magnifico bosque de Puyas Raimondi y la gruta de San Francisco, formación geológica de roca volcánica con hermosas estalactitas.

A $25 \mathrm{Km}$ de Recuay, penetrando en el Callejón, se encuentra la ciudad de Huaraz, capital del departamento. A ambos lados de la carretera asfaltada hacia Huaraz se repiten incansablemente una gran variedad de paisajes típicos. Del puente Bedoya (Km 183) parte sobre la derecha un camino hacia Olleros y Huaripampa, y la cada vez más transitada caminata hacia Chavín.

Carhuaz.- Siguiendo siempre hacia el norte la ruta del callejón, $34 \mathrm{~km}$ más allá de Huaraz se llega a Carhuaz. que se encuentra a $2688 \mathrm{msnm}$, y en cuyo trayecto se hallan los baños termales de Monterrey y el aeropuerto de Anta. La zona ubicada en la margen del río Santa, es de clima templado y agradable, con abundantes productos agrícolas, en especial fragantes frutas. En los alrededores hay zonas para la caza de venados, perdices $y$ vizcachas, asi como para la pesca de truchas.

A $8 \mathrm{Km}$ al sur de Carhuaz está la población de Marcará, de donde parte un camino carretero de $4 \mathrm{~km}$. que conduce a las fuentes minero medicinales de Chancos, cuyas virtudes curativas les han merecido el calificativo de "fuente de la juventud". Otras fuentes termales son las de La Merced y La Providencia.

Yungay.- Al continuar la ruta del Callejón de Huaylas hacia el norte se pasa por lugares donde se encontraban las ciudades destruidas por el terremoto y aluvión casi simultáneo del 31 de mayo de 1970. Hacia el oeste una gran escultura de Cristo aparece con las brazos extendidos en patético gesto de piedad. Hacia el este. asoma formidable y amenazadora la cumbre nevada del Huascarán, se ha levantado la nueva ciudad de Yungay. En las inmediaciones se levanta el cielo Pan de Azucar, donde en 1839 tuvo lugar la batalla de Yungay, junto al 
torrente del río Ancash. Precisamente esta batalla le dio el nombre de Ancash al departamento, que se llamaba Huaylas. La zona de Yungay, de clima templado, es propicia para la caza de venados, palomas, vizcachas y patos, asi como para la pesca de truchas.

Yungay, capital de la provincia homónima es el punto de partida ideal para visitar la laguna de Llanganuco y ascender al Huascarán. En Tingua se levanta un puente colgante que cruza el río Santa, con una luz de $75 \mathrm{~m}$. El puente $\mathrm{y}$ un camino de acceso unen Tingua con las comunidades de Shupluy, Cascapara, Ecash y otras.

Caraz.- Continuando el camino hacia el norte del Callejón, se llega a Caraz (capital de la provincia de Huaylas). En Caraz concluye la pista asfaltada que viene desde Pativilca. Los nevados Huandoy, Santa Cruz, Alpamayo y otros, constituyen un esplenderoso marco para la ciudad. Y en la cercana laguna de Parón se reflejan las cumbres nevadas. Hay también fuentes mineromedicinales como las de Colca y Shangor.

Los pobladores producen tejidos de lana, alfombras, ponchos, tejidos de paja y los renombrados dulces de frutas y manjarblanco denominados "cuarteados". Partiendo de Caraz hacia el norte se cruza el rlo Santa para luego llegar al famoso Cañón del Pato. El Callejón se ha estrechado entre paredes altísimas $y$ verticales de roca viva, sin ninguna vegetación $y$, en este ramo, las rocas de las coordilleras Blanca y Negra se aproximan a menos de $5 \mathrm{~m}$ de distancia.

Para llegar a Huallanca, al término norte del Callejón de Huaylas, deben pasarse 33 túneles, en un recorrido de 25. $\mathrm{Km}$ en los que el río Santa rompe, bramando la Cordillera Negra, para lanzarse en dirección al mar. De aquí continúa la carretera que conduce al llamado Callejón de Conchucos.

Huaraz.- La capital del departamento de Ancash se encuentra asentada en una explanada con ligero declive en la Cordillera Blanca, a $3027 \mathrm{msnm}$. El río Santa atraviesa la ciudad siguiendo una dirección de sur a norte y en el centro de Huaraz recibe el nombre de río Quilcay. En sus calles inmediatas al mercado de abastos aparecen las imprescindibles "paraditas" de vendedores de la artesanía ancashina: tejidos de lana de alpaca, alfombras, chompas coloridas, etc. También se encuentran los "cuarteados" de Caraz, las cajas de manjarblanco, mantequillas, quesos, miel de abejas, grandes piernas de jamón ahumado y salado, característico de la zona, etc.

A $30 \mathrm{~km}$ de Huaraz, por la vía Huaraz-Casma que cruza la Cordiliera Negra, se encuentra el punto denominado Punta Callán en la cumbre de esta coordillera, desde donde se puede observar el impresionante espectáculo de la inmensa cadena de nevados de la cordillera Blanca y la vista panorámica del Callejón de Huaylas.

\section{$3^{\circ}$ RUTA: CASMAHUARAZ (LA CORDILLERA NEGRA)}

Esta vía es poco frecuentada. La carretera comienza con un tramo asfaltado hasta Yaután, y rápidamente empieza a ascender mediante una pista afirmada por las faldas de la cordillera negra siguiendo el curso del río Casma.

La belleza de la Cordillera Blanca está determinada en gran parte por la Cordillera Negra, pues esta última suaviza los vientos provenientes del Océano Pacífico y evita, actuando como coraza, el deshielo de los grandes glaciares de la Cordillera Blanca. La Cordillera Negra posee picos rocosos con muy poca nevada invernal, alcanzando altura máxima de $5500 \mathrm{~m}$., de alli su nombre, en comparación con los blancos picos nevados de la Cordillera Blanca.

\section{$4^{\circ}$ RUTA: CHIMBOTE - HUALLANCA (EL SANTA Y EL CAÑÓN DEL PATO)}

La carretera, saliendo de Chimbote, corre en los primeros tramos por los amplios terraplenes llanos $y$ fértiles del valle del río Santa, remontando el curso de éste hasta llegar a Huallanca. El río Chuquicara es una gran afluente del Santa por su margen derecha. Desde Huallanga se puede ingresar en el Callejón de Huaylas por medio de la carretera que conduce a Caraz. También es el ingreso hacia el Callejón de Conchucos.

La Cordillera de Huayhuash que se encuentra en el límite de Ancash con el departamento de Huánuco. Tiene sólo $30 \mathrm{Km}$ de largo con caracteerísticas himalayenses y sus picos son morfológicamente mucho más quebrados y de más difícil acceso que los de la Cordillera Blanca

\section{$5^{\circ}$ RUTA LONGITUDINAL DEL ESTE: CATAC- HUALLANCA (CALLEJÓN DE CONCHUCOS)}

El Callejón de Conchucos es una bellísima sucesión de valles ubicados al este de la Cordillera Blanca, unidos por un circuito carretero de Catac hasta Huallanca. Además de las ruinas arqueológicas de Chavín de Huántar que permanentemente son visitadas por estudiosos en la materia $y$ por turistas de diversas 
nacionalidades. El Callejón de Conchucos cuenta con atractivos que la naturaleza le ha prodigado, tales como sus aguas termomedicinales, bellos paisajes, lugares de caza, y conjuntos arqueológicos que fascinaron a Julio $C$. Tello y otros especialistas.

\section{ESPECIES ANIMALES}

Especies de ganado: En el departamento de Ancash predomina el ganado ovino con 780,709 cabezas en 58,355 unidades agropecuarias; $\sin$ embargo

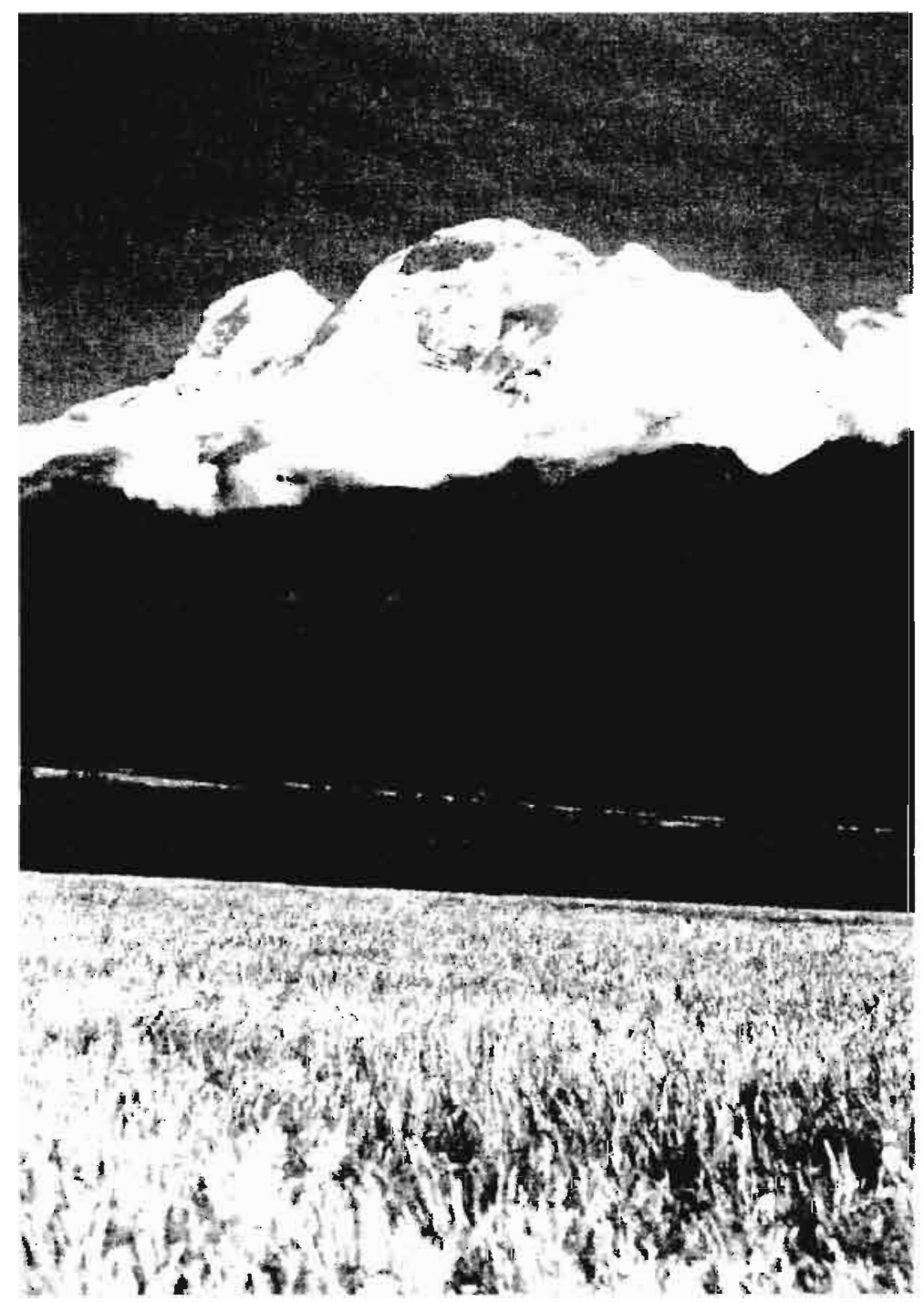

\section{PRODUCCIÓN AGROPECUARIA}

En los valles andinos: papa, maíz, trigo, cebada, ocas, ollucos.

Principales cultivos transitorios: en el departamento de Ancash: papa, maíz amiláceo, trigo, algodón, cebada grano, arroz cáscara, maíz amarillo duro,"café, frijol y oca.

Principales cultivos permanentes: manzano, palto, melocotonero-durazno, mango, naranjo, capulí, lúcumo, granadilla, chirimoyo. guayabo y tuna. encontramos también la producción de: ganados porcinos, vacuno, caprino, camélidos sudamericanos (llama, alpaca, guanaco).

Animales domésticos: cuyes, galllinas, caballos. Especies y lacustres: en la zona andina: trucha.

También identificamos fauna silvestre variada, siendo las especies más conocidas: venado gris, vicuña, oso de anteojos, taruca, puma, vizcacha, la comadreja, el gato montés, la muca, el zorrillo añaz y zorro andino. Entre las aves de la zona destacan: pichisanca o gorrión americano, tórtola y jilguerito cordilleranos, perdiz, pato 
de los torrentes, cóndor, gallareta y picaflor gigante.

\section{MAMIFEROS}

Nombre científico

Laguidiun peruanum

Duscyon culpacus

Lynchialurus pajeros

Odocoileos virginianus

Felis concolor

Conepatux rex

Vicugna vicugna

Hippocamelus antisensis

\section{AVES}

Nombre científico

Buteos poecilochnous gurney

Vultur gryphus I.

Ptiloscelys resplendens

Anas havirustris oxipetera

Chloepaga melanoptera eyton

Spinus megallaanicus paulus todd

Larus serranus tshc

Podiceps chilencis morrinson

Fulica gigantea eudovy $y$ souleyt

Plegadis ridgway aller

Melakkura phoebe delastre $y$ lees
Nombre común

Vizcacha.

Zorro andino

Gato montés

Venado

Puma

Zorrino

Vicuña

Taruca

Nombre común

Aguilucho cordillerano

Cóndor

Lique - lique

Pato sumo

Huallata huachhua

Jilguero de cabeza negra

Gaviota andina

Zambullidón pimpollo

Galleneta gigante

Gallineta chica

Picaflor negro

\section{FLORA}

La más importante y excepcional es la Puya Raimondi, planta que alcanza $12 \mathrm{~m}$ de altura y tiene un ciclo de vida de aproximadamente 100 años. La puya florece una sola vez en su vida, luego esparce sus seis millones de semillas y muere. También existen otras especies como el quinual, árbol que crece hasta cerca de los 4,600 m.s.n.m. en las quebradas de la Cordillera Blanca; quishuar, yareta, retama $y$ una amplia variedad de orquideas andinas que se encuentran en todas las vertientes de la Cordillera.

\section{DESCRIPCION CULTURAL DE LA RUTA}

\section{GRANDES MOMENTOS DE VIDA COMUNITARIA EN LA REGIÓN.-}

\section{Fiestas importantes:}

\section{ENERO}

Del 18 al 21 de enero: Caraz celebra la fiesta de la Virgen de Chiquinquirá, bailando, bebiendo y comiendo. Hay diversas actividades desde folclóricas hasta corridas

de toros. Caravanas de residentes en Lima llegan para esta fecha.

23 de enero: la Virgen de la Belenita.- se realiza todos los años en el distrito de Huaraz y tiene una duración aproximado de 4 días. En la vispera se queman fuegos artificiales y los asistentes bailan al compás de los músicos.

23 de enero: San lidefonso de Recuay.

\section{FEBRERO}

2 de febrero: En la provincia de Aija se rinde homenaje a la Virgen de la Candelaria, con la presencia de danzarines disfrazados de negros y degustación de comida típica.

Movible. Carnavales. En Huaraz y otros distritos se celebran con gran pomposidad $y$ demostraciones folclóricas en danzas, comidas y vestidos.

\section{MARZO - ABRIL}

Semana Santa: Movible. Días con variados actos para recordar el sacrificio de Cristo por la humanidad. En Huari hay procesiones durante toda la semana y pasean cada día una imagen diferente. En Luzuriaga, el Domingo de Ramos alberga a todo el pueblo, que días antes se interna en los campos para recoger las palmas que bendicen y utilizarán en las procesiones. En Carhuaz, la gente se viste de negro y guarda un verdadero duelo los días Jueves y Viernes Santo. En Huaraz hay concentración de imágenes y mucho recogimiento. En Corongo. el Viernes Santo la gente se queda en sus domicilios y hace penitencia.

\section{MAYO}

3 de mayo: Señor de la Soledad, patrono de los temblores, terremotos y calamidades. Por esta fecha llegan a Huaraz gente de todos los distritos y caseríos llevando pequeñas bandas típicas con quenas y bombos: también portan en la procesión gigantescos cirios. manufacturados por ellos. Tiene una duración de 15 días.

\section{JUNIO}

La primera semana de junio se lleva a cabo la semana del andinismo. Es uno de los eventos más importantes del Calendario Turístico Regional. Las actividades que en ella se desarrolla están orientadas a promover las principales actividades del turismo de aventura. El centro geográfico de este evento es el Callejón de Huaylas en el ambito del Parque Nacional del Huascarán. Dentro de esta festividada se celebra el Festival del Chocho (tarhui) donde participan los clubes de madres y lo preparan de diferentes formas.

8 de junio: La provincia de Raimondi organiza la fiesta de la Virgen Purísima con corridas de toros, danzas tipicas y 
venta de ganado; también se realizan representaciones de la época incaica.

22 al 24 San Juan Bautista. Pomabamba.

29 de junio: Fiesta de San Pedro en Corongo, patrono de la provincia, actividades folclóricas variadas con comida y bebida.

\section{JULIO}

8 de julio: Fiesta de Santa Isabel. Una de las fiestas más pomposas de Huaylas en la que participan numerosas bandas musicales, danzarinas $\theta$ invitados, quienes disfrutan de la actividad durante el día y la noche.

18 de julio: Virgen del Carmen en Chavín.

20 al 30 de julio: Semana Cívica de Huaraz; Gran Feria Regional, se realiza en el campo ferial de la ciudad de Huaraz, comprende aspectos de recreación, así como exposiciones de agropecuarias, artesanales, comercialles $\theta$ industriales.

25 de julio: Fiesta del Apóstol Santiago en la provincia de Aija. Actividad religiosa y popular donde los pobladores practican la yuca-canga que significa uregalo de yuca».

\section{AGOSTO}

5 al 6 Coyllur. Huaraz

15 de agosto: Fiesta de la Virgen de la Asunción, venerada en las provincias de Huari, Raimondi y Huaylas, y es celebrada en los cerros, desde donde anuncian su llegada. En Huari, además hay corridas de toros, peleas de gallo y carrera de cintas; aquí, los hombres hacen competencia a caballo al estilo medieval, tratan de jalar con un pequeño palo un aro que lleva el nombre de su amada.

20 de agosto: Feria Regional del Santa donde los habitante de la provincia venden $y$ exhiben sus productos.

29 y 30 Santa Rosa. Chiquián

30 de agosto: Gran aniversario de la provincia de Aija por su fundación. Los residentes en otras ciudades regresan a su punto de origen para celebrar con pompas esta fiesta. También en Chiquián, provincia de Bolognesi. se conmemora a Santa Rosa. Durante una semana hay música, baile, corridas de toros y fútbol.

\section{SETIEMBRE}

14 de setiembre: Fiesta de la Exaltación de la Cruz. 14 al 27 El Señor de Burgos Recuay

24 de setiembre: Fiesta de la Virgen de Las Mercedes, Carhuaz. Practicamente la fiesta comienza en los primeros días cuando los mayordomos y los novenantes empiezan a recibir obsequios de sus allegados. Los días 23 y 24 se realizan actos litúrgicos. Asimismo hay una quema de fuegos artificiales, grupos de danzantes $y$ termina la festividad con la despedida de los peregrinos.

\section{OCTUBRE}

7 al 15 de octubre: Virgen del Rosario, en Huari 12 de octubre: Fiesta patronal de la Virgen del Pilar, en Ticapampa.

28 de octubre: Yungay, fiesta chica

\section{NOVIEMBRE}

1 y 2 de noviembre: día de Todos los Santos y día de Todos los Difuntos. Las familias y amigos concurren a los diferentes cementerios del departamento para recordar a sus muertos. Hasta alli llegan acompañados de músicos comida y bebida que consumen hasta el amanecer.

\section{DICIEMBRE}

8 de diciembre: Fiesta de la Inmaculada Concepción en Taricá (Huaraz).

\section{Danzas Típicas:}

Cada pueblo ancashino tiene en su folclor numerosas y variadas danzas; $y$ otras que son comunes al folclor serrano del pais, pero con determinados ingredientes originales como el huayno, la marinera el pasacalle, el carnaval, etc. Las danzas típicas de la región son:

Antihuanquillas.- Esta danza es ejecutada por 6 o 8 bailarines al son de un arpa y dos violines. Su disfraz es una mitra ornada con flores artificales de colores. máscaras metálicas policromadas, un poncho pequeño, un chaleco de tela oscura y un pantalón azul.

Wancas o Wanquillas.- Danzan en el rompe y entrada, en el día central, y en la octava por calles y plazas con mudanza y música tradicional. Los danzantes son los que participan directamente en número de par de ocho, doce o más con vestimenta multicolor.

Shacshas.- Esta comparsa esta compuesta por 10 a 20 personas que bailan con un cautivo al centro, lleva una gorra o atuendo con espejitos o lentejuelas, una cabellera postiza con rulos, una blusa de mujer con vueltas y blonda, pantalón de colores con sus canilleras.

Las Pallas de Corongo.- Se presentan en muchos casos con el inca que lleva un vestido muy lujoso, una diadema, una pechera bordada, un cetro de plata o champi y un manto bortdado.

Cuadrillas.- Simula la lucha de dos tribus . Los salvajes pretenden raptar a la hija del duende, los anima la caja y pinkullo, mientras que a la capitana las detienen sus 
padres y las pallas son alentadas por el arpa y el violín.

Los Atahualpas.- Danza actual traída por los paramongas. Disfraces multicolores con pieles rojas, con un penacho de plumas de pavo que cubre desde la cabeza hasta la espalda, blusa de colores pañuelos y faldas con flecos.

Los Negritos.- Representan una danza satírica, están compuestos por 80 más. Danzan acompasadamente al son de del arpa, violín y trompetas con sordina (instrumento para moderar el sonido). Su disfraz compuesto por un terno negro, sombrero adornado con flores artificiales,máscara de madera o cuero

Bailes y pantomimas y las llamadas representaciones.

La Chuscada Ancashina es alegre y bailable, se combina con el pasacalle, la marinera y el triste. Muchas danzas tienen expresiones de la vida incaica $y$ virreinal; otras representan la guerra y la conquista. Es importante resaltar que la vestimenta de las «Pallas de Corongo" fue ganadora del concurso Miss Mundo 1982: se dice que la mujer corongina luce estos hermosos vestidos porque era para pedirle al inca perdón por los errores cometidos. ofreciéndole en su pechera todos sus tesoros guardados para su absolución.

\section{Caracteristicas de las Fiestas Regionales}

Las fiestas duran $3 \circ 4$ dias. La víspera se inicia con actos religiosos, la quema de avellanas y fuegos artificiales a los acordes de la banda de músicos. En el día la solemne misa diaconada que comienza a las doce del día, con la concurrencia del mayordomo y su comitiva $y$ el pueblo en general, la quema de avellanas $y$ tradicional tendida con acompañamiento de la banda, luego la procesión por el cuadrilatero de la plaza principal. Terminada la procesión el mayordomo y los invitados se dirigen a su residencia para participar del acostumbrado banquete y la histórica chicha y otros licores durante la noche.

El tercer día la gran corrida de toros, la banda de músicos, la quema de avellana y la tendida. El "capitan" va recibiendo diversos obsequios consistentes en ovejas, conejos, palomas, licores, etc., y para luego iniciar la corrida de toros en medio del entusiasmo general. Esta alegría taurina termina en la residencia del "capitán" con un baile que dura hasta el amanecer, consưmiéndose cantidades de chicha y licor.

El cuarto dia, se inicia en la casa de cada funcionario con la asistencia de los obsequiantes o "Quillis" que son agasajados, especialmente en recompensa de los obsequios hechos con anticipación que consiste en sacos de papas, docenas de carneros, una res, avelianas - fuegos artificiales. $Y$ que termina en un baile $y$ degustando los deliciosos platos regionales como el picante de cuy, la pachamanca, el frito, y la chicha de jora con otros licores.

\section{SANTUARIOS, IGLESIAS, PARQUES.}

\section{EN LO TRADICIONAL}

Bajo este título se encontrará una breve descripción de lugares de importante valor turístico: zonas arqueológicas, museos, casonas, baños termales, y toda una gama de paisajes que muestran al departamento.

\section{EN HUARAZ:}

El Jirón José Olaya - Un testimonio de la antigua ciudad de Huaraz (terremoto del 70) Actualmente es un lugar tradicional, Donde se encuentran ubicadas las "chicherías" y sitio preferido de los pobladores que se reúnen a disfrutar en forma abundante y generosa de esta ancestral bebida típica.

El Museo Regional de Huaraz - Con valiosas colecciones de cerámica y monolitos de las antiguas culturas de la región; considerada la mayor muestra de piezas líticas de nuestro pais.

El Santuario del Señor de la Soledad - Donde se venera al patrono de la ciudad de Huaraz; y durante las celebraciones los feligreses se congregan en la plaza para danzar, comer y beber en homenaje a la imagen.

Miraflores: El Rataquenua - De donde se pueda apreciar todo el panorama de la ciudad capital.

El Balcón de Judas - Desde allí se pueden ver los nevados de la cordillera.

El Criadero de truchas - Ubicado en la rivera derecha del río Quilcay (Nicrupampa), con producción tecnificada de la trucha de variedad Arco Iris.

Complejo Arqueológico de Chavín - Ubicado en el distrito de Chavín a 110 kilómetros de Huaraz, tiene como principal atractivo el templo de forma piramidal trunca $y$ construidos con enormes bloques de piedras simétricas, sobresaliendo el Lanzón Monolítico, una gigantesca piedra tallada de $4.60 \mathrm{~m}$. de alto en punta de lanza y que representa con atributos de felino, ave, serpiente. 
Huilcahuaín - Hermoso templo de plataformas superpuestas hecho íntegramente de piedra.

\section{ALREDEDORES DE LA CIUDAD:}

Monterrey - Con sus aguas termo - medicinales para el tratamiento de las enfermedades reumáticas.

Callejón de Huaylas - Un valle andino ubicado entre la Cordillera Blanca y Negra.

Recuay - Aquí se encuentran los restos arqueológicos de Pueblo Viejo.

Yungay - Ubicado a los pies del famoso nevado Huascarán $(6,768 m . n . s . m$.$) Conocido por el fatídico$ aluvión del 31 de mayo de 1970.

\section{EN LO ECOLOGICO}

Una muestra de la belleza natural del departamento: reservas ecológicas, parques nacionales, zonas de protección con una rica variedad de flora y fauna.

Parque Nacional del Huascarán - Donde destaca el nevado Huascarán (6,678 m.s.n.m.). más alto del Perú y la montaña tropical más alta del mundo. Lagunas: Parón La laguna más alta de la Cordillera Blanca $(4,200$ m.s.n.m); y donde se aprecian los nevados: Pirámide de Garcilazo, Huandoy Norte. Pisco. Chacraraju y Paria.

LLanganuco - Formada por "Chinan Cocha" llaguna hembra) y Orcon Cocha (laguna macho), caracterizadas por la incomparable colaboración de sus aguas verde turquesa; Desde alli se aprecian los nevados de Chopicalqui, Huascarán, Huandoy, Pisco, Chacraraju y Yanapaccha.

Llaca - Permite apreciar los restos arqueológicos de Huilcahuain y los nevados de Ocshapalca y Ranrapalca.

Querococha - Deja observar los nevados de Pucaraju y Yanamarey.

Quebrada de Pachacoto - Carpa - .Con los odales de la famosa Puya Raimonndi, las fuentes gasificadas de Pumapampa, el ojo de agua Pumashimi, pinturas rupestre y los nevados de Muroraju. Huarapasca y tuco.

Cañón del Pato - Una de las más importantes fuentes generadoras de energía eléctrica del país.

\section{DESCRIPCION TERRITORIAL DEL RECETARIO}

En Ancash hay variedades de platos típicos que se puede apreciar de las diferentes regiones que este conforma, así como de los lugares y pueblos que los caracterizan citaremos algunos de ellos:

En Huaraz .- Se puede degustar en los diferentes restaurantes turísticos, campestres los diversos platos típicos, como el picante de cuy, el frito, pecan caldo. patasca, pachamanca, la chicha de jora, etc.

En los alrededores también encontramos el jamón ahumado que se preparan en varios lugares. entre los cuales se cuenta, el pequeño y pintoresco hotel "Los Pinos".

En el campo.- Es característico en las fiestas regionales $y$ religiosas la preparación del cuchi canca o asado de lechón tierno, el puchero de col o repollo que es otro potaje muy estimado. la llunca o sopa de trigo con carne de res o gallinas. En las mañanas el pecan caldo para curar la cabeza. el jaca cashqui o sopa de cuy, muy estimado que solo se prepara en el campo. El picante de cuy, llamado antes cazuelado por que se preparaba en cazuela de barro. $Y$ la chicha de jora que va hasta las ultimas estancias campesinas.

En Caraz.- Hay industria casera donde se preparan dulces entre estos son muy populares, las cajas circulares con cuatro secciones diferentes de manjarblancos, por ejemplo: manjarblanco de yemas, manjarblanco corriente, jalea de sidras y jalea de tomates, estos cuatro dulces son realmente buenos aunque su elaboración es aun rudimentaria.

Huallanca.- Se aprecia a las vendedoras con sus canastas anunciando la venta de "causa" a los pasajeros que viajan hacia Chimbote. Como comprenderán muchos turistas cuando les anucian causa creen que es la que estan acostumbrados a comer en Lima $y .$. en cambio se encuentran con una gran sorpresa.

\section{RECETARIO REGIONAL}

CUCHI CANCA (chancho asado al horno)

LLUNCA CASHOUI (sopa de trigo con carne de gallina) CHARQUI DE CHANCHO

JACA CHASQUI (una variedad del picante de cuy servido como sopa)

PAPA CHASQUI (sopa hecha de papa, leche y queso frescol

YUCA SHUPE (sopa sin grasa que se sirve en las 
mañanas luego de una noche de diversión)

HUALLPA CHASQUI (caldo de gallina con nueces $y$ almendras molidas)

PECAN-CALDO (caldo de cabeza de cordero)

PACHAMANCA

PICANTE DE CUY AL ESTILO HUARACINO

PATASCA

CEBICHE DE CHOCHOS

EL CHARQUE A LA HUARACINA

CHICHA EN CALDO ( típica de Huallanca basado en gallina, chicha de jora, chancaca y pasas).

\section{PUCHERO}

\section{PIERNAS DE JAMON AHUMADO Y SALADO}

TAMAL

DULCES : Bizcochuelos, manjar blanco, cuarteados, miel de abeja, humitas de chochoca, mazamorra de calabaza, dulce de sidras, dulce de membrillo y guaguas.

BEBIDAS: Cañazo, ponche de frutas (de acuerdo a la estación), el caliche, chinnguito (trago típico de la zona de Chiquián). chicha de jora o maní, café de cebada con cañazo (bebida de velorio y entierros), machica (bebida tradicional para el desayuno hecha de cebada).

Hay una variedad de productos lácteos como queso mantecoso, quesillo y mantequilla. Cabe destacar que en la zona de chiquián se producen los mejores quesos y mantequillas.

\section{PICANTE DE CUY AL ESTILO HUARACINO}

\section{Preparación:}

Se pelan dos cuyes en agua muy caliente y se cuelgan un rato para que escurran. Aparte se prepara un aderezo de ajos, sal y comino y con este aderezo se embadurnan los cuyes por dentro y por fuera. Se ponen a cocinar inmediatamente al horno o se atraviesan con un palito y se cuecen a la brasa. Aparte se pone a sancochar dos kilos de papas peladas y cortadas en rodajas, las cuales una vez cocidas, se disponen en una fuente junto con los trozos de cuy ya listos. Se baña todo con la siguiente salsa:

Moler $1 / 2$ kilo de ají molido amarillo o colorado sin pepas y bien lavado. Poner en una sartén $1 / 2$ taza de aceite y dorar $1 / 2$ cucharada de ajo molido, agregarle el aji y unas cuatros cucharadas de maní tostado y molido. Mover bien y añadirle $1 / 2$ taza de agua en el que sancocharon las papas. Dejar cocinar unos minutos, retirar y. servir.

\section{PATASCA}

\section{Preparación:}

Se pone a hervir el maíz. Aparte se pone a hervir todo junto: la cabeza, patita, el mondongo de carnero o vaca. el tocino de chancho y jamón, y una vez sancochado se pica menudo. Se hace un aderezo: una pizca de ajos, cebolla molida, ají mirasol y colorado también molido y se fríe en manteca de chancho hasta dorar.

Este aderezo se le echa al caldo y se le agrega el mote (maíz) y agrega hierba buena y al ultimo ajíes enteros tostados. Finalmente se sirve la "patasca ".

\section{CUCHI CANCA (chancho asado)}

\section{Preparación}

El lechón se debe tener en cuenta la edad del chancho que no debe de exceder de un año. Se desuella y se desangra. Aparte en una vasija se mezcla una botella de vinagre, ajos molidos, aji mirasol molido, pimienta, comino y sal. Con estos ingredientes se embadurna los músculos mediante agujeros que se hace utilizando el cuchillo, se adoba el lechón y se deja todo un día. Luego se asa en hornos de leña.

Se sancochan las papas se cortan en rodajas y se doran. Aparte se prepara la ensalada con tomate, lechuga y cebolla.

En una asadera se pone el lechón al horno a una temperatura moderada hasta que este cocido. Luego se sirve acompañado de las papas doradas y ensalada.

\section{PECAN CALDO (caldo de cabeza)}

Preparación:

Para este plato se hace hervir la cabeza. mondongo y patitas de cordero en agua con sal y cabecillas de ajo $y$ cebolla. Una vez sancochado se cuela el caldo, la carne se pica y se agrega al caldo concentrado un poco de hierba buena $y$ aji entero tostado. Se sirve inmediatamente.

\section{AJl AHOGADO}

Preparación:

Poner en una cazuela una cantidad de manteca y llevar al fuego. Una vez caliente la manteca se le agrega el ajl molido y el rocoto molido. Cuando ya está para dorarse se le agrega "un plato " de cebolla picada, leche $y$ trozos de queso. Cuando todo esto suelte el hervor se parten huevos y se deja que cocinen. Sancochar papas y pelarlas. La cazuela se sirve acompañada con las papas.

\section{HUALLPA CASHQUI}

Preparación:

Se despresa una gallina y se pone a sancochar con sal. Una vez sancochado se le agrega unas papas crudas peladas. Aparte se prepara un aderezo de: manteca, ajos 
y ají mirasol molido y este aderezo se le agrega al caldo junto con las presas y papas. Se sirve

\section{JAMON SERRANO}

Preparación:

Una pierna de chancho se soba con sal molida y una cucharadita de salitre molida. Una vez sobada la pierna esta se prensa. Al segundo día se cubre con aji molido y finalmente se ahuma por tres días.

\section{CHARQUI A LA HUARACINA}

\section{Preparación:}

Se cortan pequeños bistecitos de lomo de chancho se salan y se ponen a secar al sol, de dos a tres, colgados de un cordel (por supuesto que si no hay sol se necesitaran mas días).

Para prepararlos se fríen en manteca muy caliente, se sancochan las papas y se cortan en rodajas, se lava la lechuga y se prepara la salsa de cebolla. Aparte se tuesta la cancha (maíz) y se corta en rodajas el ají.

Se sive acompañado con las papas. En el mismo plato se coloca una hoja de lechuga con salsa de cebolla y ají en rodajas. Aparte en un plato pequeño se pone la cancha tostada.

\section{PUCHERO}

\section{Preparación:}

Potaje preparado en base a col o repollo, aderezado con abundante ajos y "hierba buena" así como el anís de campo. Acompañan carne de res, ovino o cerdo: el preparado se realiza en peroles o pailas grandes generalmente en la casa del mayordomo. Se siven en lapas o "Ankaras" a los donantes o "kellis", los que a su ves sirven a sus amigos o familiares en pequeños mates o platos. Se degusta este potaje con abundante aji molido o rocoto.

\section{FRITO}

\section{Preparación:}

La forma como se inicia el consumo del chancho es mediante el preparado del "Frito". El potaje consiste en pequeñas porciones de cerdo cocidos en cazuelas de barro a fuego lento, una vez listo se sirve con salsa criolla y mote (maíz sancochado)

\section{HACA UCHU}

Preparación:

Se embadurna el cuy con ajos, pimienta, comino y sal, se deja macerar por lo menos una hora. Luego se pone a las brasas Aparte se pone a sancochar las papas y se prepara el aji molido. Una ves cocido el cuy se sirve de inmediato acompañado de papas cortadas en rodajas y ají.

\section{MOTE DE MAIZ}

Preparación:

El maíz blanco es sometido a un cocimiento con cenizas, producto de la quema de eucalipto, al emplearse como leña - luego lavado - Se vuelve a cocinar este, lo suficiente como para comer. Acompaña, a los chicharrones, frito y la preparación de otro plato como es el mondongo.

\section{MONDONGO}

Preparación:

Consiste en poner a hervir en una olla pedazos de vísceras de res, carnero, hierba buena y sal. Aparte se hace un aderezo especial con ajos, cebolla bien picada. Luego se le hecha al caldo junto con el mote de maíz y se deja que de un hervor. Se sirve caliente.

\section{LLUNGA CASQUI}

\section{Preparación:}

Se cocina la gallina en trozos en el agua del trigo pelado donde previamente a sido sancochado con comino y sal. Luego se prepara un aderezo con ajos y se le vierte encima del caldo. Se degusta de inmediato.

\section{CHAKUI}

Preparación:

Se hace el aderezo con cebolla bien picada, ajos, comino y sal. Aparte se disuelve la harina de alverja en una vasija con agua fría y se le agrega al aderezo, se la agrega agua y se deja hasta que hierba antes de retirar del fuego se le hecha un huevo sacudido y se sirve. Se acostumbre comer en los desayunos.

\section{TRUCHA}

Preparación:

Se limpia la trucha se condimenta con pimienta comino y sal, luego se fríe. Aparte se sancochan las papas, se pelan, cortan en rodajas y se doran. Aparte se prepara la ensalada de cebolla con lechuga y tomate. Se sirve la trucha, al rededor las papas y a un costado la ensalada. También se suele servir la trucha con una guarnición de ensaladas. 


\section{LA CHICHA DE JORA}

Preparación:

Es una bebida preparada con maíz germinado, hervido. Este se guarda, en cántaros o "cuntus," luego es curado con Chancaca derretida y azúcar y antes de ser consumido se endulza al gusto. También se toma entreverado con "washcu"

\section{PACHAMANCA}

Preparación:

Este potaje se realiza en un horno hecho en la tierra. Se sazona las diferentes carnes de cerdo, carnero, res con el chinchu, perejil y culantro. Se condimenta con la pimienta, comino y sal, se masajea y se deja un rato macerar. Luego en el horno se pone una cama de piedras calientes, luego una capa de hoja de plátano que este limpia, se pone la carne las habas, las papas y el choclo. Se tapa con una capa de hojas de plátano y encima piedras calientes. Se deja cocinar una hora y se sirve.

\section{JACA CASHOUI}

Preparación:

Se pela el cuy y se pone a que escurra. Se troza el cuy se pone en una olla a hervir. Luego se hace un aderezo con el ajo, el comino y la sal y se le agrega al caldo junto con las papas peladas y cortadas en trozos. Se sirve al momento. Este plato solo se prepara en la zona del campo.

\section{HUMITAS DE CHOCHOCA}

Preparación

Se prepara la masa con diez huevos por cada libra de chochoca cernida manteca y azúcar al gusto. Los huevos se baten hasta que queden cremosos $y$ es entonces cuando se añaden la chochoca y la manteca. La masa se coloca en una panca de choclo y se rellena con queso y pasas bien envueltas $y$ atadas, las humitas se hierven en baño maría.

\section{LLAGHUARI}

Preparación:

A base de papas, olluco, trigo pelado, huevos y carne, acompañado de una cachanga (especie de tortilla de harina con manteca).

\section{CALICHE}

Preparación:

También conocido como Chingirito o "Calentito", preparado a base de té, canela, hierbas aromáticas que se sirve con limón y una copa de alcohol.

\section{GASTRONOMIA, SOCIEDAD Y CULTURA REGIONAL}

\section{RELACIÓN ENTRE LOS UNIVERSOS SIMBÓLICOS DE LA REGIÓN Y LA COCINA:}

* El 08 de julio se festeja en Huaylas la fiesta más popular del departamento de Ancash en honor a la virgen de Santa Isabel patrona de las cosechas, imagen que se encuentra abrazada a la Virgen María, razón por la cual los pobladores en señal de buen augurio le regalan mazorcas dobles (espiga densa y apretada como la del maiz o cacao).

* En el marco de estas festividades, siguiendo una antigua costumbre, las muchachas casaderas nombran al varón de sus preferencias como "compadre de carnaval", representándose al ahijado mediante unas muñecas de harina llamadas guaguas.

* El 25 de Julio se celebra la fiesta del apóstol Santiago en Aija, quien es el patrono. En esta se practica la llamada Yuca-Canga, que quiere decir regalo de yucas. Es religiosa y muy popular. El que celebra la fiesta debe ir a la entrada del pueblo a esperar a otro que le regale las yucas y verduras traldas de la quebrada. Con todos los regalos entra al pueblo dejándolos en todas las casas.

- Según fuentes orales de los pobladores del Callejón de Huaylas, comentan que durante la permanencia del sabio italiano Antonio Raimondi, luego de haber visitado la localidad de Huari, en la zona de los Conchucos, llegó a la ciudad de Recuay. Muy cansado por el viaje quedó profundamente dormido en la Plaza Principal, dejando una recua de mulas cargadas con todo su material de trabajo y al despertarse se dió con la sorpresa que sus acémilas y equipos hablan desaparecido como por arte de magia, por tal motivo decidieron bautizar la ciudad como "Recuay Ladronera".

- Luego se dirigió a la ciudad de Huaraz, en la cual estuvo en amores con una joven huaracina, pero parece que no le fue muy bien con esta dama por los continuos desplantes que sufría, entonces decidieron ponerle el apelativo "Huaraz Presunción". 
* Continuó su recorrido hacia la ciudad de Carhuaz, llego durante la festividad de la Virgen de las Mercedes, los carhuacinos celebraron esta fiesta con grandes cantidades de caliche (aguardiente); chicha de jora, por esta razón le pucieron el nombre de "Carhuaz Borrachera".

* Terminando su estancia se dirigió a la ciudad de Yungay, la cual era muy hermosa por sus casonas, y bellos jardines, paisajes únicos, etc.; Por este motivo le puso el nombre de "Yungay Hermosura".

* Y por último visitó la ciudad de Caraz, la que se caracteriza por la elaboración de dulces, manjarblanco. cuartedo, rosquitas, jaleas y otros; fue asi como le puso el apelativo "de Caraz Dulzura".

* En una oportunidad pude observar a los miembros de una comunidad campesina ubicada en la parte alta de la ciudad de Yungay, camino a la zona de Llanganuco donde acudió una delegación de altos funcionarios del gobierno central para la colocación de la "primera piedra" de un albergue turístico, los cuales fueron agasajados con una "pachamanca" en el lugar preferencial le sirvieron de forma abundante carne de cordero, cerdo y pollo con papàs $y$ habas, a manera de homenaje. En otro espacio estaban reunidos los comuneros, para sorpresa mía solo se sirvieron papas y habas; luego de algún tiempo queda como recuerdo "la piedra fundamental" y se sigue esperando la construcción del albergue.

\section{ENTORNO CULTURAL DEL RECETARIO:}

* Fiesta gastronómica conocida como la Tablada de Acopalca, consiste de un tablón en forma triangular cubierto de frutas y panes con un lechón en el medio que es llevado en festiva procesión- encabezado por dos guaguas de pan vestidas como niños- hasta la zona de la trillada para competir con otras dos procesiones similares. Ahí se inicia la fiesta que dura toda la noche hasta que se acaba toda la comida y el trago.

* El 02 de febrero se celebra la fiesta de la Virgen de la Candelaria en toda la región, es una fiesta religiosa, pero en ella se presentan gran cantidad de danzarines disfrazados de negros y se sirven comidå̉s típicas.

* Es costumbre de todo ancashino después de vísperas de fiesta en las mañanas toman su PECAN-CALDO para recuperar las fuerzas que perdieron al no dormir durante la noche.
* Es costumbre que en la fiesta de Santa Isabel 108 de julio) se sirva el sancochado y la gente no toma otra bebida que no sea chicha de jora; esto en Huaylas.

* El 20 de agosto se celebra la fiesta del señor de Santa, es a manera de una pequeña feria regional, durante la cual se venden y exhiben todos los productos de la provincia. Hay peleas de gallos, corridas de toros $y$ procesión. El mismo día se celebra el día de Santo Toribio de Mogrovejo en Mácate (Santa), se presentan bailes. peleas de gallos, y ferias populares con venta de productos típicos.

* En el "Huachihualito" (cortamonte) árbol de capulí vestido en carnaval. Se sirven a todos los participantes una sopa de cordero y el típico de seco de cordero.

* El día 07 de octubre se celebra la fiesta de la Virgen del Rosario en Bolognesi. Es muy ceremoniosa y presenta números folclóricos tanto en danzas como en comidas y vestimenta.

* El 01 de noviembre se conmemora la Fiesta de todos los Santos, en Sihuas, con demostraciones folklóricas. Fiesta de tipo religioso con procesiones y adoraciones de los muertos. Algunos llevan comidas al cementerio en la creencia de que la acción alegra a los muertos.

* En la última semana de junio se celebra la Semana del Andinismo, y siempre se incluye un Festival de Viandas Típicas.

* El sabio antonio Raymondi bautizó a Caraz como "dulzura" debido a los dulces tan exiquisitos que encontró allí, es muy conocido el "cuarteado", dulce de frutas con manjarblanco. Es muy típico que los turistas hagan sus compras de manjarblanco, cuarteados y otros dulces en Caraz, la mayoría de las agencias de viaje lo incluyen como parte de su itinerario.

\section{SOCIEDAD REGIONAL Y GASTRONÓMICA.}

Debido a su variedad de climas y territorio. Ancash posee potajes que satisfacen los gustos más exigentes.Además de las variedades de cebiche y platos a base de pescado y mariscos que pueden saborearse en la costa, en la sierra son muy pedidos los picantes de cuy al estilo huaracino, el jaca-chasqui, la papa-chasqui, la yuca-shupe, el pecán-caldo, la huallpa-chasqui y las humitas de chochoca. 
- Los platos típicos de Ancash son a base de carne de cuy, aves, cerdo y ovinos. También se usa mucho el maíz (la chochoca que es un maíz casi tierno, molido). Las sopas y los caldos menudean, lo mismo que una infinidad de panecillos y que tienen diversos significados en las distintas festividades. Las piernas de jamón salado y ahumado es otra especialidad de la culinaria ancashina que buscan mucho los turistas.

- Los pueblos de Ticapampa y Recuay (antiguamente un lugar de trueque de granos por mulas) producen un maiz pequeño, tierno y particularmente muy DULCE.

- El sabor del cuy es especial, pues se fríe en manteca de chancho, puesto casi nunca falta esta manteca; pues por lo menos una vez al año se mata dicho animal.

* En la fiesta de Santa Isabel el Picante de Cuy por única vez se sirve con Locro de Trigo (trigo, carne bastante ajî).

- Es típico el CHOCHO que es como arveja sacada de la vaina, del color del garbanzo, como si fuera un poroto. Le llaman TARWI.Tiene tantas proteínas como la carne, es barato y crece hasta los 5.000 m.s.n.m.. La Oficina de alimentación Agraria se suma cada año al festival del chocho. Los huaracinos diecen:" Vamos mascando, comiendo bien rico com coquita (coca) para los labios. Se puede preparar una variedad de platos como salsa picante de chocho. humitas y tamales, picante, pepián. hamburguesas, cuy con crema de chocho, cebiche de chocho, también alfajores de chocho y galletas de chocho.

\section{CONCLUSIONES}

Se puede concluir, que en estos tiempos de globalización, estandarización, donde proliferan la comida chatarra, que se expende en cadenas de restaurantes nacionales $y$ extranjeros.

La ruta gastronómica del Callejón de Huaylas ofrece ventajas comparativas culinarias, que la hacen diferente del resto de los destinos turísticos, pero que necesariamente debería sumar ventajas competitivas relacionadas a la calidad del servicio, la cual todavia resulta insuficiente, porque se nota una falta de conciencia turística.

Es importante destacar el enorme potencial turístico que cuenta el Callejón de Huaylas, merece la atención de los profesionales de las Ciencias Administrativas a efectos de preparar e implementar proyectos de inversión en servicios turísticos.

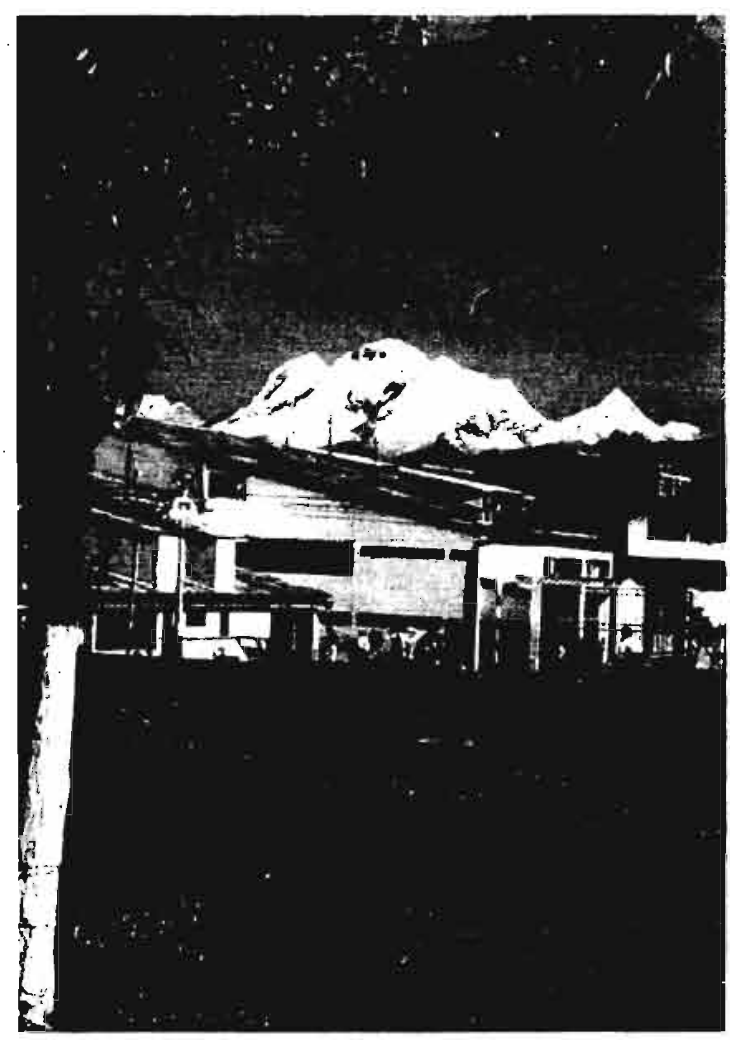




\section{B I B L I O G R A F I A}

\section{1.- FERNANDO CABIESES}

Agricultura y Nutrición en el Perú

Banco Agrario-Lima-1998

02.- GUIA TURISTICA PERU

Editorial Labrusa- Lima- 1985
03.- FELIPE DIAZ BUSTOS

Callejon de Huaylas

Lima-1985

Empresarial Mc.Graw-Hill. Bogotá.

(") Licenciado en Turismo y Hoteleria, de la UPSMP. Docente de la Facultad de Ciencias Administrativas - Escuela de Administración de Turismo UNMSM y de la Universidad Particular Ricardo Palma, Consultor de Empresas de Turismo y Hotelerfa. Ex Decano del Colegio de Licenciados en Turismo del Perú. Miembro del Instituto de Investigaciones de la Facultad de Ciencias Administrativas UNMSM 


\section{Programa de Investigación en la Facultad de Ciencias Administrativas}

\section{Gestion desairolo empresana}

Modelos y estilos de gestión

Creatividad e innovación empresarial

Tecnología de la información

Teoría general de sistemas

\section{Promoción empresarial}

Cooperación y alianzas estratégicas

Proyectos de inversión y sociales

Gobiernos locales

Empresas de servicios

Gestión del comercio exterior

\section{Geston y os arrollo de ootenclat humano}

Administración de la calidad

Desarrollo organizacional

Estrategias de desarrollo del potencial humano

\section{Planeamerto del Desarrollo Empresanal}

Planeamiento estratégico

Sistematización, localización de información y espacios

Potencial del mercado nacional e internacional

\section{Gestionjurico administrativo}

Gestión del arbitraje y conciliación

Auditoría administrativa

Adminstracian tuncional

Logística

Marketing

Finanzas

Operaciones

Sistemas de información 